\title{
Firsthand or secondhand data in school labs: It does not make a difference
}

\author{
Burkhard Priemer ${ }^{1,{ }^{*}}$ Stephan Pfeiler, ${ }^{2}$ and Tobias Ludwig $\oplus^{3}$ \\ ${ }^{1}$ Humboldt-Universität zu Berlin, Department of Physics-Physics Education; \\ Newtonstr. 15, 12489 Berlin, Germany \\ ${ }^{2}$ Immanuel-Kant-Gymnasium, 10317 Berlin, Germany \\ ${ }^{3}$ Karlsruhe University of Education, Institute for Physics and Technical Education, 76133 Karlsruhe, Germany
}

(Received 26 June 2019; accepted 27 January 2020; published 9 March 2020)

\begin{abstract}
We report the findings of an empirical study that investigated whether the source of data-firsthand or secondhand data gained from lab work experiments-has an influence on students' learning outcomes. Results indicate that students' choice of a correct or incorrect hypothesis for a pendulum lab experiment on the influence of the mass of the bob on the time of oscillation does not depend on who the author of the data at hand is: the student themself, a peer, or a teacher. Further, students judge the importance of the data's author as relatively unimportant no matter what data source they have at hand. Thus, it seems fairly unimportant whether students use firsthand or secondhand data when the teaching focus is set on choosing a correct hypothesis in the light of empirical data, as long as students get enough information on how the data were generated and how they are analyzed and interpreted. This result is especially relevant for practitioners, as it shows that it is possible to use secondhand data for the purpose of evaluation and interpretation without significant distortions of epistemic learning processes.
\end{abstract}

DOI: 10.1103/PhysRevPhysEducRes.16.013102

\section{INTRODUCTION}

Analyzing and interpreting data, including but not limited to lab work, is a core topic in 21 st century science education [1]. In school labs, students often generate firsthand data. It is assumed that this involvement in the data acquisition process supports learning: for example, data ownership may lead to a better data analysis [2], a more careful planning of investigations [3], a deeper understanding and better learning outcomes [4], and more interest in science [5]. However, students may distrust their own data, and by doing so, become uncertain about how to interpret the gained results [6]. This may lead students to rely more on prior knowledge or beliefs than on the data at hand $[2,7]$. Finally, it is possible that the learning outcomes depend on the expertise a student assigns to the author when using secondhand data. For example, a student may trust the results of others $[8,9]$ and hence may avoid their own active involvement in the task [10].

Even though the question of the influence of the data source-firsthand or secondhand data — on students' learning achievements sounds straightforward, there is

\footnotetext{
Corresponding author. priemer@physik.hu-berlin.de

Published by the American Physical Society under the terms of the Creative Commons Attribution 4.0 International license. Further distribution of this work must maintain attribution to the author(s) and the published article's title, journal citation, and DOI.
}

surprisingly little research on it. And the results do not allow clear conclusions. This is why we argue that this question is still open.

\section{RESEARCH ON THE USE OF FIRSTHAND AND SECONDHAND DATA}

It is tempting to quickly distinguish between firsthand and secondhand data when characterizing a data source. Students can generate their own firsthand data in experiments or use secondhand data from school books or web sources. However, this distinction becomes somewhat fuzzy when, for example, a teacher generates data in the classroom. Here, it is not precisely clear if students perceive the data as firsthand or secondhand. Thus, we conclude that a dichotomic distinction between firsthand and secondhand data seems inappropriate. It is more of a continuum of the amount of the students' own involvement in producing the data at hand that seems important [7] (p. 1726).

Given this view on firsthand and secondhand data, Delen and Krajcik [11] report that students create stronger explanations when analyzing firsthand data compared to secondhand data. In their study, 116 students from four sixth-grade classes collected firsthand data from a local water source and were given secondhand data from another schools' project. After analyzing these data, they were asked to write an explanation for the results. The authors explain their results by stating that the "absence of involvement might have (...) hindered student ability to make sense of the data collection environment when 
creating explanations" [11] (p. 1969). This is in line with results from Magnusson, Palincsar, Lomangino, and Hapgood [12]. They report "some evidence that encountering a second-hand investigation (...) following a first-hand investigation advanced student development of scientific reasoning" [12] (p. 10). Here, the experience of working with firsthand data seems to have prepared the 48 fourth-grade students to appropriately use secondhand data. However, in this setting it is hard to judge how big the influence of the data source was. In addressing this issue, the authors state that, generally, there were no differences between the firsthand and secondhand groups.

This indicates that it is not clear how much data ownership influences student learning. Data ownership is a term used here to describe that students actively created data that they own afterward. Data ownership may influence the ways in which students handle and evaluate data, e.g., their "willingness to critique and discuss the limitations around it" [7] (p. 1746) or their motivation to take much greater effort to grasp its meaning [7]. In their study with 74 seventh-grade biology and chemistry students, Hug and McNeill [7] investigated students' discussions that were based on firsthand and secondhand data. The authors report that the percentage of accurate and data-based conclusions was higher in the firsthand data group, while the percentage of accurate drawing on content knowledge was higher in the secondhand group. These results give divergent evidence for which data source is more beneficial.

This brief glance into the research shows that, so far, there is no clear answer to the question of how much influence the use of firsthand or secondhand data has on students' achievements in science. This is partly due to the different dependent variables that were under investigation in the different studies (e.g., content learning, argumentation, explanation, and interest). Further, we see the following problem in some studies that compare firsthand and secondhand data: in these comparative studies, the groups differed not only in the data source (firsthand and secondhand) but also in other variables like students' engagement with a topic or time on task [11], the content addressed [7,12], or the complexity of the data $[7,12]$. This makes the comparisons somewhat confounding. Hence, we see a need to discover whether the data source alone makes a difference.

\section{RESEARCH QUESTION}

Does the source of the data-self-generated (firsthand), provided by a peer (secondhand), or provided by a teacher (secondhand) - have an influence on student learning outcomes (measured by the choice of a hypothesis about the result of an experiment in physics)?

\section{METHOD}

This research question was addressed in the context of a bigger study [13]. Here, we report only what is relevant to answer this particular question.

We conducted an experimental study with 42 ninth graders (22 girls and 20 boys, average age: 14.5 years) in two urban high schools in Germany. Two different schools were chosen to keep the administrational effort (obtaining legal agreement of the school district) reasonable. The students were recruited from six different classes and participated voluntarily at the end of regular classes. In a pretest, all students were asked what influence the mass of a simple pendulum bob has on the time of oscillation (for the complete text of the question see the Appendix). Three multiple-choice, single-select options to choose a hypothesis were given: the bigger the mass, (1) the longer the time of oscillation, (2) the shorter the time of oscillation, or (3) the mass has no influence on the time of oscillation. In addition to choosing one of these initial hypotheses, the students had to justify their choice in written text to minimize the chances of them simply guessing. This procedure has shown to be fruitful in other studies [10].

TABLE I. Dataset given to the secondhand peer and teacher group and example of a firsthand dataset.

\begin{tabular}{|c|c|c|c|c|c|c|}
\hline \multirow[b]{2}{*}{$\begin{array}{l}\text { No. of measurement for the } \\
\text { time of five oscillations (in sec.) }\end{array}$} & \multicolumn{2}{|c|}{ Mass $1(50 \mathrm{~g})$} & \multicolumn{2}{|c|}{ Mass $2(100 \mathrm{~g})$} & \multicolumn{2}{|c|}{ Mass $3(150 \mathrm{~g})$} \\
\hline & $\begin{array}{l}\text { Secondhand peer } \\
\text { and teacher }\end{array}$ & Firsthand & $\begin{array}{l}\text { Secondhand peer } \\
\text { and teacher }\end{array}$ & Firsthand & $\begin{array}{l}\text { Secondhand peer } \\
\text { and teacher }\end{array}$ & Firsthand \\
\hline 1 & 7.00 & 7.12 & 7.00 & 7.01 & 7.15 & 6.98 \\
\hline 2 & 7.10 & 7.10 & 7.04 & 7.04 & 7.00 & 7.00 \\
\hline 3 & 7.06 & 7.09 & 7.01 & 7.15 & 7.09 & 7.09 \\
\hline 4 & 7.12 & 7.12 & 6.98 & 7.06 & 7.17 & 7.00 \\
\hline 5 & 7.01 & 7.00 & 7.00 & 7.10 & 7.10 & 7.00 \\
\hline 6 & 7.04 & 7.10 & 7.02 & 7.01 & 7.07 & 7.02 \\
\hline 7 & 7.04 & 7.12 & 7.07 & 7.07 & 7.02 & 6.98 \\
\hline 8 & 7.07 & 7.00 & 7.06 & 7.07 & 7.12 & 7.02 \\
\hline 9 & 7.00 & 7.17 & 7.09 & 7.04 & 7.10 & 7.06 \\
\hline 10 & 7.00 & 7.07 & 7.00 & 7.04 & 7.15 & 7.01 \\
\hline
\end{tabular}


TABLE II. Correct solution of the analysis of the datasets.

\begin{tabular}{|c|c|c|c|c|c|c|}
\hline & \multicolumn{2}{|c|}{ Mass $1(50 \mathrm{~g})$} & \multicolumn{2}{|c|}{ Mass $2(100 \mathrm{~g})$} & \multicolumn{2}{|c|}{ Mass $3(150 \mathrm{~g})$} \\
\hline & $\begin{array}{l}\text { Secondhand peer } \\
\text { and teacher }\end{array}$ & Firsthand & $\begin{array}{l}\text { Secondhand peer } \\
\text { and teacher }\end{array}$ & Firsthand & $\begin{array}{l}\text { Secondhand peer } \\
\text { and teacher }\end{array}$ & Firsthand \\
\hline Mean time for one oscillation (in sec.) & 1.41 & 1.42 & 1.41 & 1.41 & 1.42 & 1.40 \\
\hline $\begin{array}{l}\text { Maximal difference between the mean } \\
\text { value for one oscillation and all } \\
\text { measurements (in sec.) }\end{array}$ & 0.02 & 0.02 & 0.02 & 0.01 & 0.02 & 0.02 \\
\hline
\end{tabular}

Then, all students conducted the same guided experiment: measuring the time of five oscillations ten times for three different bob masses. Hence, all students had the same experiences concerning the data generation. After this lab work, the participants were randomly assigned to three groups. Participants of all three groups were drawn from each of the six classes to avoid class effects. One group used their self-generated data for their analysis (firsthand), a second group handed in their results and were provided with "new" data that we declared as data from a peer (secondhand peer), and a third group handed in their results and were provided with "new" data that we declared as data from a teacher (secondhand teacher). However, both secondhand datasets were the same and the firsthand dataset had the same quality as the secondhand data sets (Table I). To analyze their datasets, the students were instructed to calculate the mean and the maximal difference between the mean and all measurements for one oscillation (as an estimation of the uncertainties) in each of the data columns for the three masses. The results for the three masses were compared with respect to whether the uncertainty intervals overlapped.

The correct solutions of this analysis are given in Table II. As can be seen, all three means have uncertainty intervals that overlap. Hence, when using this method of estimating the uncertainties, the datasets suggest that there is no influence of the mass on the time of oscillation [14].

The participants reviewed their initial hypothesis in light of the evidence in a post-test which was identical to the pretest. Again, they had to justify their choices. Students' answers to the initial and reviewed hypothesis were analyzed with respect to the correctness (correct solution: the mass of the bob has no influence on the time of oscillation). Finally, the students had to put four different given aspects of the data-generating procedure into an order with respect to how important they think these aspects are when judging the data's trustworthiness: characteristics of the experiment (e.g., how the experiment is conducted), characteristics of the author who generated the data (e.g., the author's expertise), characteristics of the data (e.g., statistical features), and relations of the data to other references (e.g., agreement with theoretical predictions). During the study, groups were not allowed to exchange any task-related information.

\section{RESULTS}

In three participants' answers to the pretest and the posttest, we had missing data, so these students were not included in the analysis of the correct and incorrect solutions. In the pretest, only $13 \%$ of the students had a correct hypothesis, which is in line with the former research $[2,10]$. This number increased to $59 \%$ in the post-test. Thus, we argue that students' work with the datasets led to an increase of correct solutions no matter if they used firsthand or secondhand data.

All five students with a correct initial hypothesis gave the correct answer in the post-test as well (see Fig. 1). The answers of these students give no information whether the source of the data has an influence on learning outcomes. To give an answer to the research question, we looked at those 34 students that had an incorrect initial hypothesis. Figure 1 shows how many of these students changed to the correct hypothesis or kept one of the incorrect hypotheses.

We found no significant association between the variables "group" and the "correctness of students' hypothesis" $\left[\chi^{2}(2)=0.654 p=0.76\right.$; corrected with a Fisher's exact
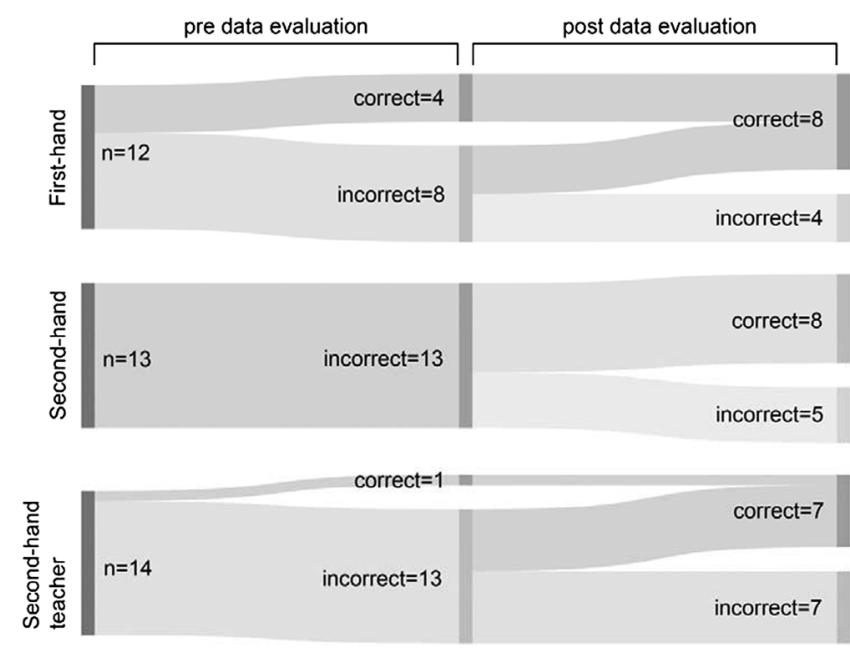

FIG. 1. Number of students with a correct hypothesis or one of the incorrect hypotheses in the pretest and the post-test for the three groups. 


\section{- most important $\square$ 2nd most important \\ $\square$ 3rd most important $\square$ 4th most important}

45

40

35

30

25

20

15

10

5

0
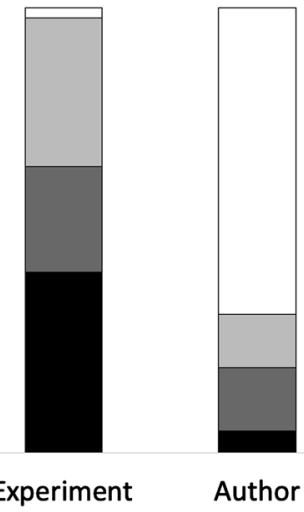

Author

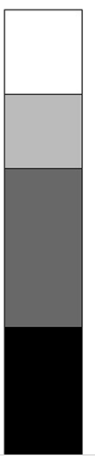

Data

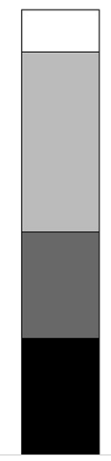

Relations
FIG. 2. Students' ratings of how important the four aspects of the data-generating procedure are (full sample $N=42$ ).

test due to the low number of participants in the different groups [15]].

The students' ratings of how important the four aspects of the data-generating procedure (experiment: characteristics of the experiment, author: characteristics of the author who generated the data, data: characteristics of the data, relations: relations of the data to other references) are when judging the data's trustworthiness are shown in Fig. 2. Here, we show the results for the full sample $(N=42)$ because there were no missing answers for this question. Obviously, the author was seen as least important. We found a significant relation between the variables "aspect of the data-generating procedure" and "the importance rating"

\section{most important $\square$ 2nd most important $\square$ 3rd most important $\square$ 4th most important}

16

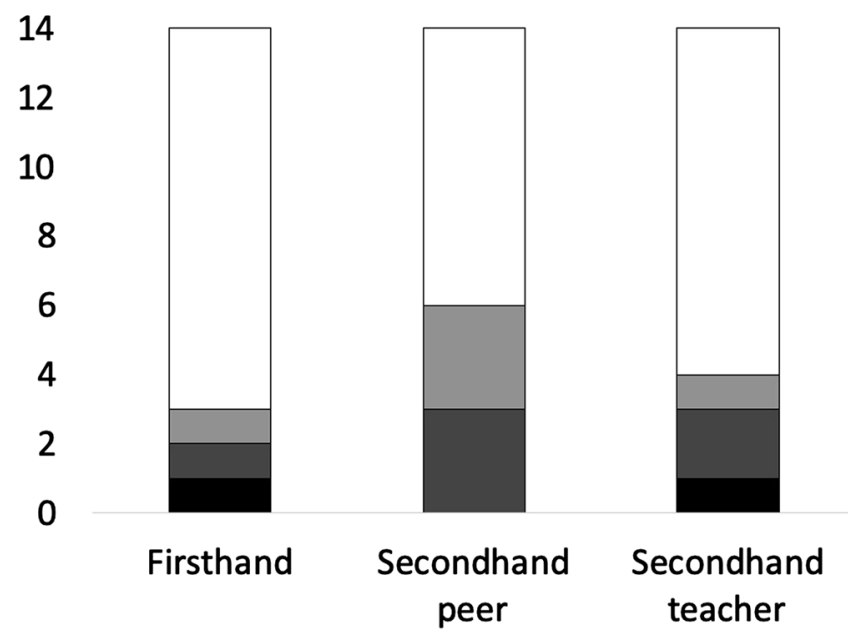

FIG. 3. Students' ratings of how important the author who generated the data is (full sample $N=42$ ). $\left[\chi^{2}(9)=69.93, p<0.05 ;\right.$ Kruskal-Wallis test: $H(3)=$ 42.51, $p<0.001$; additional tests-that are not reported here-indicate that the significant difference originates from the aspect "characteristics of the author who generated the data"].

Further, we looked for differences in the ratings of the author's importance between the three groups. Figure 3 shows that the ratings are quite similar. We found no significant relation between the variables "group" and "the importance rating" $\left[\chi^{2}(6)=4.08, p>0.5\right.$; Kruskal-Wallis test: $H(3)=0.99, p>0.05$; this result is true for the other three aspects of the data-generating procedure as well].

\section{DISCUSSION}

Our results show that the source of data (firsthand, secondhand peer, secondhand teacher) has no effect on students' learning outcomes when these are measured by the choice of the correct or one of the incorrect hypotheses. In addition, students' ratings of how important the data's author is do not differ between the groups. Thus, when varying only the source of the data-without varying, for example, students' involvement in the data-generating process at the same time-it does not make a difference whether students use firsthand or secondhand data.

This result must be viewed with respect to the limitations of our study: we operationalized learning outcomes by the choice of hypotheses only, the number of participating students was relatively small, we used only one topic in physics, we focused only on the activity of comparing data sets, and we chose only one experimental activity to generate data. Future investigations should address these issues and, thus, can support or refute the claim we make about the nonexistent influence of the data sourcefirsthand and secondhand data-on learning outcomes.

Our result, which is in line with Ref. [12], can be interpreted in light of the critique we outlined above: When comparative studies on this topic vary not only the data source but also additional variables (like time spent on a task, knowledge of the data-generating process, or amount of communication about the topic) simultaneously, these uncontrolled factors may make the difference. If only the source is varied, as in our study, then these effects disappear.

Within the conditions of our study, this can be explained when we assume that students put more emphasis on the experimental setting and on the nature of the data than on the data source when analyzing their results. When asked which characteristic students rate as the most important when analyzing data, "Characteristics of the author who generated the data" is seen as the least important. Students in the secondhand groups may have perceived the given data as similar to their own and hence see a confirmation of the validity of their own data. However, if students perceive the given data as in disagreement with their own the importance of the source of the data may be judged differently. In our study, the complexity of the data that 
all students gathered was rather moderate and all students were able to work with the data. So, there seemed to be no reason for the students not to rely on their own data which, again, explains why the author is seen as unimportant. However, if the students lack knowledge in how to deal with data, they may rate the authors role differently $[10,6]$. In summary we can conclude the following: If students went through a data generating process, their ability to process the data and their beliefs about the data seem to influence their choice of a hypothesis about the result of an experiment and their judgment about the importance of the source of the data.

Thus, our study supports the view that it seems fairly unimportant whether students use firsthand or secondhand data when choosing between different hypotheses, as long as students know how the data were generated. This is relevant for practitioners since it is not always possible to collect large datasets in the classroom. Our results indicate that it may be sufficient if students exemplarily generate own data and then continue on with larger secondhand data sets that are perceived as in agreement with the own data.

\section{ACKNOWLEDGMENTS}

We acknowledge support by the German Research Foundation (DFG) and the Open Access Publication Fund of Humboldt-Universität zu Berlin.

\section{APPENDIX: PRETEST AND POST-TEST QUESTION}

The following question was used as a pretest and as a post-test.

A pendulum consists of a bob that is attached to a fixed string and that can swing freely. The pendulum can be described by the following quantities:

- the time of oscillation: the time it takes for a complete oscillation, e.g., to swing from the resting position (string points perpendicular to the ground) all the way to the right, then all the way to the left, and back to the resting position.

- the length of the string to which the bob is attached to

- the mass of the bob

- the angular displacement: the angle between the following two positions of the pendulum (1) resting position and (2) starting position

It can be assumed that the time of oscillation, the length of the string, the mass of the bob, and the angular displacement are somehow related.

What is your hypothesis?

The bigger the mass...

() the longer the time of oscillation.

() the shorter the time of oscillation.

() the mass has no influence on the time of oscillation.

Please tick one of these options and justify your choice briefly.
[1] V. R. Lee and M. Wilkerson, Data use by middle and secondary students in the digital age: A status report and future prospects, Commissioned Paper for the National Academies of Sciences, Engineering, and Medicine, Board on Science Education, Committee on Science Investigations and Engineering Design for Grades 6-12 (National Academies of Sciences, Washington, DC, 2018).

[2] Z. Kanari and R. Millar, Reasoning from data: How students collect and interpret data in science investigations, J. Res. Sci. Teach. 41, 748 (2004).

[3] B. Hug and J.S. Krajcik, Students' scientific practices using a scaffolded inquiry sequence, in Proceedings of the International Conference of the Learning Sciences, edited by P. Bell, R. Stevens, and T. Satwicz (Lawrence Erlbaum Associates, Seattle, WA, 2002).

[4] H. Schecker, Integration of experimenting, and modeling by advanced educational technology: Examples from nuclear physics, in The International Handbook of Science Education, edited by K. Tobin and B. J. Fraser (Kluwer, Dordrecht, The Netherlands, 1998), Part I, pp. 383-398.

[5] J. Osborne, S. Collins, M. Ratcliffe, R. Millar, and R. Duschl, What 'Ideas-bout-science' should be taught in school science? A Delphi study of the expert community, J. Res. Sci. Teach. 40, 692 (2003).
[6] K. Kok, B. Priemer, W. Musold, and A. Masnick, Students' conclusions from measurement data: The more decimal places, the better?, Phys. Rev. Phys. Educ. Res. 15, 010103 (2019).

[7] B. Hug and K. L. McNeill, Use of first-hand and second-hand data in science: Does data type influence classroom conversations?, Int. J. Sci. Educ. 30, 1725 (2008).

[8] R. E. Petty and J. T. Cacioppo, The elaboration likelihood model of persuasion, in Advances in Experimental Social Psychology, edited by L. Berkowitz (Academic Press, Orlando, Florida, 1986), Vol. 19, pp. 123-205.

[9] D. Kienhues, E. Thomm, and R. Bromme, Specificity Reloaded-How Multiple Layers of Specificity Influence reasoning in Science Argument Evaluation, in Scientific reasoning and Argumentation-The Role of DomainSpecific and Domain-General Knowledge, edited by F. Fischer, C. A. Chinn, K. Engelmann, and J. Osborne (Routledge, New York, 2018), pp. 251-270.

[10] T. Ludwig, B. Priemer, and D. Lewalter, Assessing secondary school students' justifications for supporting or rejecting a scientific hypothesis in the physics lab, Res. Sci. Educ. https://doi.org/10.1007/s11165-019-09862-4 (2019). 
[11] I. Delen and J. Krajcik, What do students' explanations look like when they use second-hand data?, Int. J. Sci. Educ. 37, 1953 (2015).

[12] S. J. Magnusson, A. S. Palincsar, S. Hapgood, and A. Lomangino, How should learning be structures in inquiry-based science instruction? Investigating the interplay of 1st- and 2nd-hand investigations, in Proceedings of the Sixth International Conference of the Learning Sciences, edited by Y. Kafai, W. Sandoval, N. Enyedy, A. Nixon, and F. Herrera (Lawrence Erlbaum Associates, Inc., Mahwah, NJ 2004), pp. 310-317.
[13] S. Pfeiler, Die Evaluation von Daten aus erster und zweiter Hand im naturwissenschaftlichen Unterricht [The evaluation of firsthand and secondhand data in science lessons] (Ph.D. thesis), Humboldt-Universitätzu Berlin, 2019.

[14] B. Priemer and J. Hellwig, Learning about measurement uncertainties in secondary education: A model of the subject matter, Int. J. Sci. Math. Educ. 16, 45 (2018).

[15] A. Field and J. Miles, Discovering Statistics Using R (Sage, London 2012). 